\title{
Stromal cells of the mouse spleen
}

\section{Joke M. den Haan, Reina E. Mebius and Georg Kraal*}

Department of Molecular Cell Biology and Immunology, VU University Medical Center, Amsterdam, Netherlands

\section{Edited by:}

Christopher G. Mueller, Centre National de la Recherche Scientifique, France

\section{Reviewed by:}

Geneviève Milon, Institut Pasteur, France

Peter Balogh, University of Pécs, Hungary

${ }^{*}$ Correspondence:

Georg Kraal, Department of Molecular cell Biology and Immunology, VU

University Medical Center, PO Box

7056, 1007MB Amsterdam,

Netherlands.e-mail: g.kraal@vumc.nl
The composition and function of stromal cells in the white pulp of the spleen resemble to a large extent the situation in other secondary lymphoid organs such as lymph nodes. The stromal cells play an important role in the support and guidance of lymphocytes and myeloid cells in the T and B cell zones of the spleen. Major differences of the spleen are found in the way cells enter the white pulp and the composition of stromal cells in the red pulp. In this review, the features of stromal cells of both white and red pulp will be described in light of the function of the spleen.

Keywords: spleen, white pulp, red pulp, fibroblast reticular cells, marginal zone, marginal reticular cell

\section{INTRODUCTION}

The structure and organization of the spleen differ in many aspects from other secondary lymphoid organs such as lymph nodes, related to the complex function of the spleen as a filter of the blood as well as a lymphoid organ. The spleen is composed of compartmentalized lymphoid tissue, the white pulp, which resembles the organization of lymph nodes (Mebius and Kraal, 2005). The venous part of the spleen, the red pulp, is composed of intricate blood endothelial sinuses lined with macrophages, essential for particle clearance of the blood and removal of effete red blood cells. In addition to the immune and filter function of the spleen, the organ is a large reservoir of monocytes and can play a role in hematopoiesis during ontogeny and under pathological conditions. This variety of functions will be reflected in the local composition and function of stromal cells in the spleen, such as fibroblast reticular cells (FRC) and endothelial cells. Here, we will describe what is known about the different stromal cell types in the compartments of the spleen and their contribution to the function of the organ.

\section{ONTOGENY}

The distinct position of the spleen is reflected in its ontogeny. The molecular and cellular requirements that are essential for the development of lymph nodes and mucosa associated lymphoid organs have been described in large detail. Studies in mice deficient in various genes have made it clear that the interaction of lymphoid-tissue inducer (LTi) cells and stromal lymphoid tissue organizer (LTo) cells is crucial for the development of lymph nodes (Mebius, 2003). The hematopoietic LTi cells, expressing lymphotoxin- $\alpha 1 \beta 2$, seed the lymph node anlage and interact with the mesenchymal LTo cells that express the lymphotoxin- $\beta$ receptor (LT $\beta R$ ). The interaction between the two cell types and the resulting upregulation of adhesion molecules, cytokine and chemokine production is instrumental for further local development of lymph nodes (Vondenhoff et al., 2009b). Interestingly, deficiency of either the lymphotoxin receptor or ligand leads to a complete absence of lymph node development. Similarly, deficiencies described for genes that are crucial for the differentiation or the homing and clustering of LTi cells prevent the formation of lymph nodes (Yoshida et al., 2002; Vondenhoff et al., 2009a). Yet, under all these circumstances the spleen will still be formed. In fact, products of the HOX genes, which play a more central role in embryogenesis, are necessary for spleen formation (Brendolan et al., 2007), with $\mathrm{Pbx} 1$ as the prime regulator of spleen organogenesis (Koss et al., 2012). Interestingly, LTi cells can be detected in the fetal spleen where they can be found at the periphery of the white pulp anlagen (Vondenhoff et al., 2008). Expression of homeostatic chemokines in stromal and endothelial cells suggests that LTi cells are attracted by these chemokines. As lymphotoxin- $\alpha 1 \beta 2$ can be detected on $B$ cells but not on LTi cells in neonatal spleen, the earliest formation of the white pulp in fetal spleen occurs in an LT $\alpha 1 \beta 2$-independent manner (Vondenhoff et al., 2008).

Although lymphotoxin signaling is not required for the formation of the white pulp and the segregation of red and white pulp, it is important for an optimal functional development of the lymphoid part of the spleen (Futterer et al., 1998). In its absence, T and B cell compartments do form but $B$ cell follicles lack functional follicular dendritic cells (FDCs) and there is a conspicuous absence of macrophages in the marginal zone. This impaired development can be the result of altered induction of chemokines that are necessary for the homing and retentions of lymphocytes and dendritic cells (DCs). That B cells play an important role in this process was demonstrated in mice that lack B cells (Ngo et al., 2001; Nolte et al., 2004). A profound effect was seen on the organization of the splenic T cell zone (periarteriolar lymphoid sheath, PALS) and on the number of DCs in the white pulp. This was dependent on the production by stromal cells of CCL21, a T cell zone chemokine, and the induction of gp38 (podoplanin) expression, a stromal cell marker. This induction required the interaction of $\mathrm{B}$ cell and stromal cells and depended on LT $\alpha 1 \beta 2$ expression by B cells (Ngo et al., 2001). 
In other studies, it was demonstrated that the chemokines CCL21, and to a lesser extent CCL19, are involved in the localization of the marginal zone macrophages in the marginal zone (Ato et al., 2004).

\section{STROMAL CELLS IN THE SPLEEN: THE WHITE PULP}

Even though it is obvious that stromal cells are important for the organization of the white pulp and marginal zone, the question is whether there are differences between stromal cells from spleen and other lymphoid organs. The organization of the white pulp of the spleen in discrete T and B cell areas closely resembles that of the lymph nodes, but there are two major differences, the absence of high endothelial venules (HEVs) and the absence of a subcapsular sinus.

High endothelial venules are crucial for the entrance of naïve, recirculating lymphocytes from the blood into the lymph nodes. In the absence of the homeodomain transcription factor Nkx2-3 HEV do develop in the spleen and can mediate L-selectindependent homing of lymphocytes (Czompoly et al., 2011). In a normal spleen, both lymphocytes and antigen will enter the lymphoid white pulp from the surrounding marginal zone (Bajenoff et al., 2008). Here, the blood vessels partially end and blood-borne antigens will be picked up by macrophages and DCs, whereas lymphoid cells can actively migrate into the white pulp, depending on the expression of adhesion molecules and chemokine receptors. From homing studies using blocking antibodies the involvement of the adhesion molecules LFA-1 and $\alpha 4 \beta 1$ on migrating cells and the ligands ICAM-1 and VCAM-1 on stromal cells has been inferred (Nolte et al., 2002; Lo et al., 2003).

Data from intravital microscopy have confirmed earlier observations that lymphocytes predominantly enter the white pulp from the marginal zone via the bridging channels and from there into the $\mathrm{T}$ cell-dependent area surrounding the central arteriole (Bajenoff et al., 2008). These bridging channels are also involved in the exit of effector cells that have been activated in the white pulp and leave for the red pulp or further dissemination into the blood (Figure 1).

The migration of cells into the white pulp is an active process by which a layer of stromal cells, the marginal reticular cells (MRC) has to be passed. These cells form the boundary between marginal zone and the $\mathrm{T}$ and $\mathrm{B}$ cell areas of the white pulp and are characterized by the expression of MAdCAM-1 and the production of CXCL13 (Katakai et al., 2008). Furthermore, the production of chemokines by these cells may lead to the formation of local niches for cells in the marginal zone, such as the marginal zone $\mathrm{B}$ cells and the marginal metallophilic macrophages, and possibly DCs.

The position of the MRC at the border of marginal zone and white pulp emphasizes the overall structural resemblance of the white pulp with a lymph node. In a lymph node, the MRC form the bottom of the subcapsular sinus and play a similar role as in the marginal zone of the spleen by regulating cell entrance into the T cell zone (Katakai et al., 2008; Koning and Mebius, 2012).

In addition, MRC are in close contact with CD169 expressing metallophilic macrophages in the spleen and subcapsular macrophages in the lymph nodes and may be involved in their generation and maintenance. Recent studies indicate that these

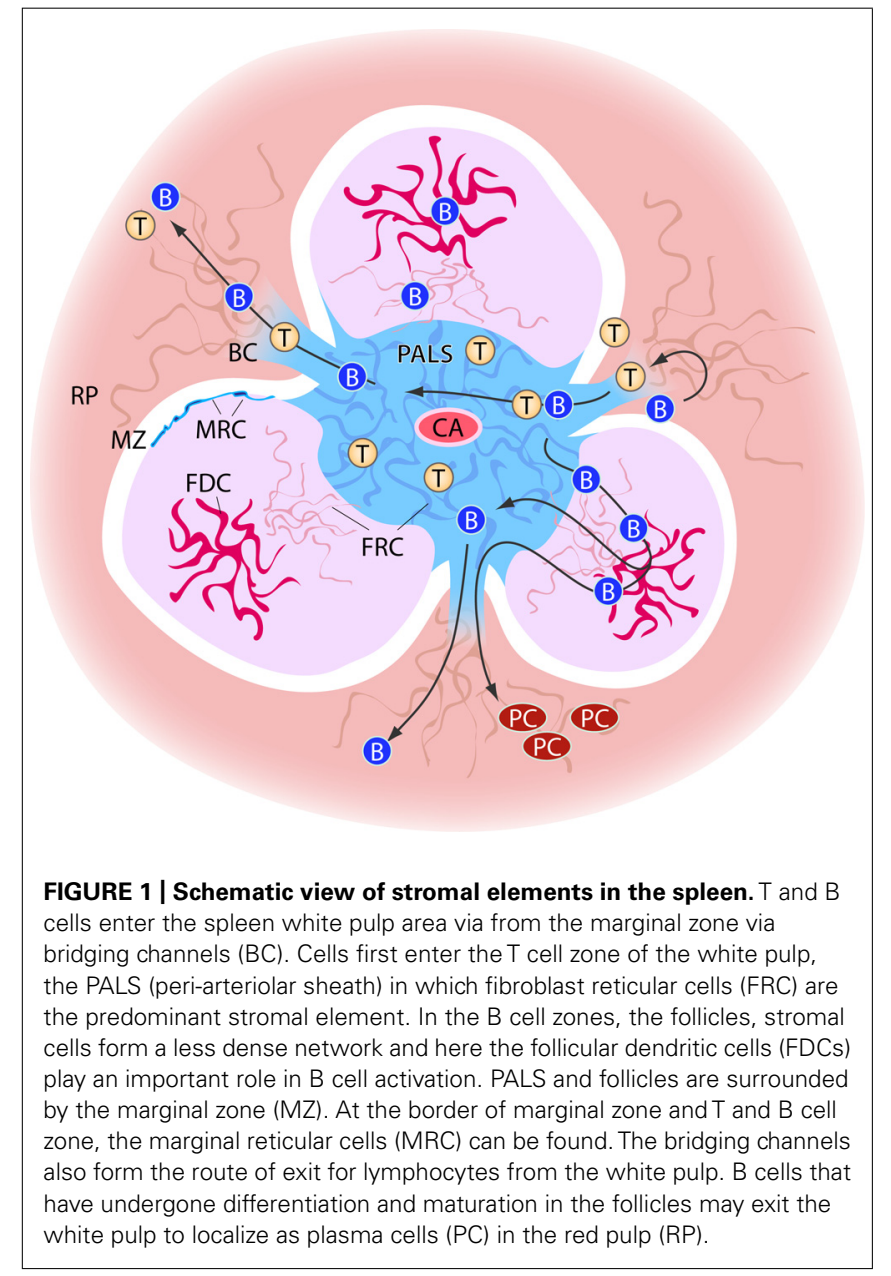

macrophages have important functions in both the innate and the adaptive immune system by producing type I IFN and viral antigens after infection, by transferring antigens to B cells and DCs, and by directly stimulating NKT cells (Phan et al., 2009; Vondenhoff et al., 2009b; Backer et al., 2010).

Once lymphoid and myeloid cells have entered the white pulp they are able to migrate further along a network of stromal cells, the FRC. The network extends throughout the T cell zone of the white pulp and is connected to the marginal zone (Mueller and Ahmed, 2008). Although the structure of the FRC network in the spleen has not been studied in as much detail as has been done for the comparable network in lymph nodes, based on functional studies it is very likely that the overall composition is similar to the lymph node situation.

In contrast to most connective tissues, in which the extracellular components that are produced by the fibroblasts surround the cells, in lymphoid organs a special adaptation leads to a situation where the fibroblasts surround the extracellular matrix they produce. In addition, the FRC are connected to each other forming a three-dimensional reticulum, and lymphocytes fill up the spaces of this network (Gretz et al., 1997). The extracellular matrix is highly organized in a collagen fiber network, consisting of 20-200 parallel bundles, up to 1 micron in diameter, of 
mostly type I and type III collagen fibers. The complete ensheathment of the collagen bundles by a basement membrane forms a tube and the meshwork inside, formed by collagen and connecting fibrils and associated glycosaminoglycans, results in a molecular sieve through which small molecules and fluid can be transported (Lammermann and Sixt, 2008; Roozendaal et al., 2008). This tubular system is called the conduit, and an important issue of the conduit system is the size exclusion, which is set at approximately $70 \mathrm{kDa}$ in the spleen (Nolte et al., 2003). Molecules or particles with a larger size cannot enter the conduit and be distributed.

Because all the FRC are connected, transport of molecules through these tubes over larger distances can be rapidly achieved. In the lymph node, it has been established that this conduit system acts as a messenger system to transport signal molecules like chemokines and cytokines from the draining region of the lymph node to the port of entry for lymphocytes, the HEV. Chemokines produced at a site of inflammation would reach the lymph node with the afferent lymph and quickly be transported to the HEVs via the conduit system. The conduit system ends in a perivenular region surrounding the venule and it is assumed that the chemokines can be transported to the lumen of the vessel by active transcytosis and presented there to attract blood-borne cells, such as lymphocytes, monocytes, or even granulocytes, to enter the node depending on the types of transported chemokine. In the spleen, a similar function of the conduit system can be envisaged, again with the difference that lymphocyte exit from the blood directly into the $\mathrm{T}$ cell zone has never been demonstrated. Nevertheless, an effect of small regulatory molecules on the regulation of blood distribution between marginal zone and red pulp may can be envisaged.

Although the majority of ECM products and fibers are inside the fibers, it has recently been shown that a substantial amount of matrix proteins such as laminin, fibronectin, collagen IV, and tenascin were also present on the outer surface (Sobocinski et al., 2010). These proteins can act as anchorage sites for lymphocyte to crawl along the fibers and also function as docking molecules for chemokines.

FRC also actively produce the homeostatic chemokines CCL19 and CCL21, which are ligands for CCR7 present on naïve T cells (Luther et al., 2000). These chemokines function to keep the T cells in an active migratory state, whereby they continuously move along the FRC and associated DCs. CCL19 is also involved in the homeostasis of T lymphocytes, together with the survival factor IL7, which is also produced by the FRC (Link et al., 2007). Recently, CXCL12 was shown to be localized on FRC and involved in the migration of plasmacytoid DCs into the white pulp (Umemoto et al., 2012). In addition, podoplanin expressing stromal cells of the $\mathrm{T}$ cell zone stimulated LTi survival in an IL-7-independent manner (Hou et al., 2010). Furthermore, a recent study indicated a direct stimulatory role for fibroblastic reticular cells in the activation of cytotoxic $\mathrm{T}$ cells during viral infection via the production of the alarmin IL-33 (Bonilla et al., 2012).

In the $\mathrm{B}$ cell follicles, an important stromal cell can be identified which is central for B cell immunity, the FDCs. When B cell follicles develop during ontogeny the reticular framework of FRC is replaced by a less dense network of FDCs. This replacement is not complete and a conduit system still exists in adult B cell follicles where it provides an efficient mechanism for delivery of small antigens and chemokines such as CXCL13 to B cells that are in direct contact with the conduits (Roozendaal et al., 2009). Larger antigens and complexes are transported into the follicles by macrophages. In addition, it has been shown that marginal zone $\mathrm{B}$ cells can shuttle between the marginal zone and follicles using a combination of the chemokine receptor CXCR5 and the sphingosine 1-phosphate receptors S1P1 and S1P3 (Cinamon et al., 2008). This is regarded as an additional mechanism for systemic antigen capture and delivery to FDCs and may not involve migration via the bridging channels. FDCs trap and present antigen to B cells via the binding of immune complexes to complement receptors 1 and 2 and $\mathrm{Fc}_{\gamma}$ RIIb (El Shikh et al., 2010). In addition, they provide survival and proliferation signals to both naïve $B$ cells and germinal center B cells and thereby are necessary for the integrity of both primary B cell follicles and germinal centers (Wang et al., 2011). The factors secreted by FDCs include BAFF (Gorelik et al., 2003), IL-6, and the chemokine CXCL13 to attract B cells (Ansel et al., 2000). FDC generation is dependent on LT $\alpha 1 \beta 2$ and TNF $\alpha$ expression by $\mathrm{B}$ cells and there are no differences reported between lymph node and splenic FDCs.

\section{OTHER STROMAL CELLS IN THE SPLEEN}

With minor local differences the general picture of the stromal network of the lymphoid compartment as an important scaffold in the $\mathrm{T}$ and $\mathrm{B}$ cell zones is quite comparable between spleen and lymph nodes. In addition, the spleen contains the red pulp. This compartment has unique venous sinuses in which the lining endothelial cells are positioned in parallel way. The endothelial cells contain stress fibers that run along the long axis of the endothelial cells and which are attached to annular fibers that run around the sinuses (Mebius and Kraal, 2005). Contraction of the stress fibers leads to the formation of small slits between the endothelial through which red blood cells can leave the sinuses for the venous system of the spleen. Membrane stiffening as a result of aging will eventually prevent erythrocytes from leaving the sinuses and will result in elimination by macrophages present in these sinuses. For the human spleen is has been suggested that endothelium-derived littoral cells are important for this process of filtration and elimination (Ogembo et al., 2012).

In addition to the presence of these red pulp macrophages with their important function in erythrocyte turnover and iron metabolism, the spleen is also a reservoir of macrophage precursors, monocytes (Swirski et al., 2009), which are thought to reside in the red pulp. This monocyte depot can play an important role under circumstances of acute inflammation, where rapid recruitment of monocytes leads to improved clinical outcome, as has been demonstrated in a model of acute myocardial infarction (Leuschner et al., 2012). Interestingly, in a mouse tumor model it has recently been demonstrated that the spleen also harbors neutrophil precursor cells and that both the monocyte and neutrophil reservoir can lead to tumor progression by infiltrating the tumor (Cortez-Retamozo et al., 2012). The recruitment of the cells from the spleen was mediated by the chemokine receptor CCR2. Based on histology, it was deduced that the myeloid progenitor 
cells were located in the red pulp of the spleen. Hematopoietic niches have been described in red pulp sinuses, closely associated with endothelial cells (Kiel et al., 2005), but how exactly the maintenance of myeloid progenitor cells and extramedullary hematopoiesis is supported by stromal cells in the red pulp needs further study.

The red pulp is also an important site for the localization of effector cells that have been generated in the white pulp or have migrated from other lymphoid organs. In particular, plasma cells are retained in large numbers in the red pulp. It is clear that this position enables a rapid transport of the secreted immunoglobulins into the blood and subsequently throughout the body.

During their differentiation plasma cells show increased chemotactic sensitivity to the CXCR4 ligand CXCL12 and exhibit reduced responsiveness to the $\mathrm{B}$ and $\mathrm{T}$ zone chemokines CXCL13, CCL19, and CCL21. The CXCR4 ligand CXCL12 is expressed within splenic red pulp, indicating that as B cells differentiate into plasma cells they undergo a change in chemokine responsiveness that promotes their retention in the red pulp (Ellyard et al., 2005; Hargreaves etal., 2001). In a study on human stromal cells, it was shown that stromal cells that expressed

\section{REFERENCES}

Ansel, K. M., Ngo, V. N., Hyman, P. L., Luther, S. A., Förster, R., Sedgwick, J. D., Browning, J. L., Lipp, M., and Cyster, J. G. (2000). A chemokinedriven positive feedback loop organizes lymphoid follicles. Nature 406, 309-314.

Ato, M., Nakano, H., Kakiuchi, T., and Kaye, P. M. (2004). Localization of marginal zone macrophages is regulated by $\mathrm{C}-\mathrm{C}$ chemokine ligands 21/19. J. Immunol. 173, 4815-4820.

Backer, R., Schwandt, T., Greuter, M., Oosting, M., Jüngerkes, F., Tüting, T., Boon, L., O’Toole, T., Kraal, G., Limmer, A., and den Haan, J. M. (2010). Effective collaboration between marginal metallophilic macrophages and CD8+ dendritic cells in the generation of cytotoxic $\mathrm{T}$ cells. Proc. Natl. Acad. Sci. U.S.A. 107, 216-221.

Bajenoff, M., Glaichenhaus, N., and Germain, R. N. (2008). Fibroblastic reticular cells guide $\mathrm{T}$ lymphocyte entry into and migration within the splenic T cell zone. J. Immunol. 181, 3947-3954.

Bonilla, W. V., Frohlich, A., Senn, K., Kallert, S., Fernandez, M., Johnson, S., Kreutzfeldt, M., Hegazy, A. N., Schrick, C., Fallon, P. G., Klemenz, R., Nakae, S., Adler, H., Merkler, D., Löhning, M., and Pinschewer, D. D. (2012). The alarmin interleukin-33 drives protective antiviral CD8(+) $\mathrm{T}$ cell responses. Science 335, 984-989.

Brendolan, A., Rosado, M. M., Carsetti, R., Selleri, L., and Dear, T. N. (2007). Development and function of the mammalian spleen. Bioessays 29, 166-177.

Cinamon, G., Zachariah, M. A., Lam, O. M., Foss, F. W. Jr., and Cyster, J. G. (2008). Follicular shuttling of marginal zone B cells facilitates antigen transport. Nat. Immunol. 9, 54-62.

Cortez-Retamozo, V., Etzrodt, M., Newton, A., Rauch, P. J., Chudnovskiy, A., Berger, C., Ryan, R. J., Iwamoto, Y., Marinelli, B., Gorbatov, R., Forghani, R., Novobrantseva, T. I., Koteliansky, V., Figueiredo, J. L., Chen, J. W., Anderson, D. G., Nahrendorf, M., Swirski, F. K., Weissleder, R., and Pittet, M. J. (2012). Origins of tumor-associated macrophages and neutrophils. Proc. Natl. Acad. Sci. U.S.A. 109, 2491-2496.

Czompoly, T., Labadi, A., Kellermayer, Z., Olasz, K., Arnold, H. H., and Balogh, P. (2011). Transcription factor Nkx2-3 controls the vascular identity and lymphocyte homing in the spleen. J. Immunol. 186, 69816989.

Ellyard, J. I., Avery, D. T., Mackay, C. R., and Tangye, S. G. (2005). Contribution of stromal cells to the migration, function and retention of plasma cells in human spleen: potential roles of CXCL12, IL-6 and CD54. Eur. J. Immunol. 35, 699-708.

El Shikh, M. E., El Sayed, R. M., Sukumar, S., Szakal, A. K., and Tew, J. G. (2010). Activation of B cells by antigens on follicular dendritic cells. Trends Immunol. 31, 205-211.

Futterer, A., Mink, K., Luz, A., KoscoVilbois, M. H., and Pfeffer, K. (1998).

CXCL12 were able to produce IL-6, an important factor for antibody production, and expressed the adhesion molecule CD54, which is a ligand for CD11a, which is found on plasma cells (Ellyard et al., 2005).

\section{CONCLUDING REMARKS}

Both in the white pulp and in the red pulp of the spleen different stromal cells make up the basic framework of the respective compartments. Through differential production of chemokines and growth factors stromal cells can form local niches that are essential for the maintenance and function of a variety of cell types. In the white pulp, these niches are essential for the generation of immune responses. In the red pulp, stromal cells are involved in the localization of effector cells such as plasma cells, but they have also been suggested to be central to the support of myeloid progenitor cells. Together, the data emphasize the important role of various stromal cells in creating microenvironments with highly specific functions in lymphoid organs. Future work is needed to further phenotype the different stromal cell subsets that mediate these specific functions, further allowing the identification of the different molecules involved in these processes.

The lymphotoxin beta receptor controls organogenesis and affinity maturation in peripheral lymphoid tissues. Immunity 9, 59-70.

Gorelik, L., Gilbride, K., Dobles, M., Kalled, S. L., Zandman, D., and Scott, M. L. (2003). Normal B cell homeostasis requires $\mathrm{B}$ cell activation factor production by radiation-resistant cells. J. Exp. Med. 198, 937-945.

Gretz, J. E., Anderson, A. O., and Shaw, S. (1997). Cords, channels, corridors and conduits: critical architectural elements facilitating cell interactions in the lymph node cortex. Immunol. Rev. 156, 11-24.

Hargreaves, D. C., Hyman, P. L., Lu, T. T., Ngo, V. N., Bidgol, A., Suzuki, G., Zou, Y. R., Littman, D. R., and Cyster, J. G. (2001). A coordinated change in chemokine responsiveness guides plasma cell movements. J. Exp. Med. 194, 45-56.

Hou, T. Z., Mustafa, M. Z., Flavell, S. J., Barrington, F., Jenkinson, E. J., Anderson, G., Lane, P. J., Withers, D. R., and Buckley, C. D. (2010). Splenic stromal cells mediate IL-7 independent adult lymphoid tissue inducer cell survival. Eur. J. Immunol. 40, 359-365.

Katakai, T., Suto, H., Sugai, M., Gonda, H., Togawa, A., Suematsu, S. Ebisuno, Y., Katagiri, K., Kinashi, T., and Shimizu, A. (2008). Organizerlike reticular stromal cell layer common to adult secondary lymphoid organs. J. Immunol. 181, 6189-6200.

Kiel, M. J., Yilmaz, O. H., Iwashita, T., Yilmaz, O. H., Terhorst, C., and Morrison, S. J. (2005). SLAM family receptors distinguish hematopoietic stem and progenitor cells and reveal endothelial niches for stem cells. Cell 121, 1109-1121.

Koning, J. J., and Mebius, R. E. (2012). Interdependence of stromal and immune cells for lymph node function. Trends Immunol. 33 , 264-270.

Koss, M., Bolze, A., Brendolan, A., Saggese, M., Capellini, T. D., Bojilova, E., Boisson, B., Prall, O. W., Elliott, D. A., Solloway, M., Lenti, E., Hidaka, C., Chang, C. P., Mahlaoui, N., Harvey, R. P., Casanova, J. L., and Selleri, L. (2012). Congenital asplenia in mice and humans with mutations in a Pbx/Nkx2-5/p15 module. Dev. Cell 22, 913-926.

Lammermann, T., and Sixt, M. (2008). The microanatomy of T-cell responses. Immunol. Rev. 221, 26-43.

Leuschner, F., Rauch, P. J., Ueno, T., Gorbatov, R., Marinelli, B., Lee, W. W., Dutta, P., Wei, Y., Robbins, C., Iwamoto, Y., Sena, B., Chudnovskiy, A., Panizzi, P., Keliher, E., Higgins, J. M., Libby, P., Moskowitz, M. A., Pittet, M. J., Swirski, F. K., Weissleder, R., and Nahrendorf, M. (2012). Rapid monocyte kinetics in acute myocardial infarction are sustained by extramedullary monocytopoiesis. J. Exp. Med. 209, 123-137.

Link, A., Vogt, T. K., Favre, S., Britschgi, M. R., Acha-Orbea, H., Hinz, B., Cyster, J. G., and Luther, S. A. (2007). Fibroblastic reticular cells in lymph nodes regulate the homeostasis of naive T cells. Nat. Immunol. 8 , 1255-1265. 
Lo, C. G., Lu, T. T., and Cyster, J. G. (2003). Integrin-dependence of lymphocyte entry into the splenic white pulp. J. Exp. Med. 197, 353-361.

Luther, S. A., Tang, H. L., Hyman, P. L., Farr, A. G., and Cyster, J. G. (2000). Coexpression of the chemokines ELC and SLC by $\mathrm{T}$ zone stromal cells and deletion of the ELC gene in the plt/plt mouse. Proc. Natl. Acad. Sci. U.S.A. 97, 12694-12699.

Mebius, R. E. (2003). Organogenesis of lymphoid tissues. Nat. Rev. Immunol. 3, 292-303.

Mebius, R. E., and Kraal, G. (2005). Structure and function of the spleen. Nat. Rev. Immunol. 5, 606-616.

Mueller, S. N., and Ahmed, R. (2008). Lymphoid stroma in the initiation and control of immune responses. Immunol. Rev. 224, 284-294.

Ngo, V. N., Cornall, R. J., and Cyster, J. G. (2001). Splenic T zone development is B cell dependent. J. Exp. Med. 194, 1649-1660.

Nolte, M. A., Arens, R., Kraus, M., van Oers, M. H., Kraal, G., van Lier, R. A., and Mebius, R. E. (2004). B cells are crucial for both development and maintenance of the splenic marginal zone. J. Immunol. 172, 3620-3627.

Nolte, M. A., Belien, J. A., SchadeeEestermans, I., Jansen, W., Unger, W. W., van Rooijen, N., Kraal, G., and Mebius, R. E. (2003). A conduit system distributes chemokines and small blood-borne molecules through the splenic white pulp. J. Exp. Med. 198, 505-512.

Nolte, M. A., Hamann, A., Kraal, G., and Mebius, R. E. (2002). The strict regulation of lymphocyte migration to splenic white pulp does not involve common homing receptors. Immunology 106, 299-307.

Ogembo, J. G., Milner, D. A. Jr., Mansfield, K. G., Rodig, S. J., Murphy, G. F., Kutok, J. L., Pinkus, G. S., and Fingeroth, J. D. (2012). SIRPalpha/CD172a and FHOD1 are unique markers of littoral cells, a recently evolved major cell population of red pulp of human spleen. J. Immunol. 188, 4496-4505.

Phan, T. G., Green, J. A., Gray, E. E., Xu, Y., and Cyster, J. G. (2009). Immune complex relay by subcapsular sinus macrophages and noncognate $B$ cells drives antibody affinity maturation. Nat. Immunol. 10, 786-793.

Roozendaal, R., Mebius, R. E., and Kraal, G. (2008). The conduit system of the lymph node. Int. Immunol. 20, 1483-1487.

Roozendaal, R., Mempel, T. R., Pitcher, L. A., Gonzalez, S. F., Verschoor, A., Mebius, R. E., von Andrian, U. H., and Carroll, M. C. (2009). Conduits mediate transport of low-molecular-weight antigen to lymph node follicles. Immunity 30, 264-276.

Sobocinski, G. P., Toy, K., Bobrowski, W. F., Shaw, S., Anderson, A. O., and Kaldjian, E. P. (2010). Ultrastructural localization of extracellular matrix proteins of the lymph node cortex: evidence supporting the reticular network as a pathway for lymphocyte migration. BMC Immunol. 11, 42. doi: 10.1186/1471-2172-11-42

Swirski, F. K., Nahrendorf, M., Etzrodt, M., Wildgruber, M., CortezRetamozo, V., Panizzi, P., Figueiredo,
J. L., Kohler, R. H., Chudnovskiy, A., Waterman, P., Aikawa, E., Mempel, T. R., Libby, P., Weissleder, R., and Pittet, M. J. (2009). Identification of splenic reservoir monocytes and their deployment to inflammatory sites. Science 325, 612-616.

Umemoto, E., Otani, K., Ikeno, T., Verjan Garcia, N., Hayasaka, H., Bai, Z., Jang, M. H., Tanaka, T., Nagasawa, T., Ueda, K., and Miyasaka, M. (2012). Constitutive plasmacytoid dendritic cell migration to the splenic white pulp is cooperatively regulated by CCR7- and CXCR4mediated signaling. J. Immunol. 189, 191-199.

Vondenhoff, M. F., Desanti, G. E. Cupedo, T., Bertrand, J. Y., Cumano, A., Kraal, G., Mebius, R. E., and Golub, R. (2008). Separation of splenic red and white pulp occurs before birth in a LTalphabetaindependent manner. J. Leukoc. Biol. 84, 152-161.

Vondenhoff, M. F., Greuter, M., Goverse, G., Elewaut, D., Dewint, P., Ware, C. F., Hoorweg, K., Kraal, G., and Mebius, R. E. (2009a). LTbetaR signaling induces cytokine expression and up-regulates lymphangiogenic factors in lymph node anlagen. J. Immunol. 182, 5439-5445.

Vondenhoff, M. F., van de Pavert, S. A., Dillard, M. E., Greuter, M., Goverse, G., Oliver, G., and Mebius, R. E. (2009b). Lymph sacs are not required for the initiation of lymph node formation. Development 136, 29-34.

Wang, X., Cho, B., Suzuki, K., Xu, Y., Green, J. A., An, J., and Cyster, J. G.
(2011). Follicular dendritic cells help establish follicle identity and promote $B$ cell retention in germinal centers. $J$. Exp. Med. 208, 2497-2510.

Yoshida, H., Naito, A., Inoue, J., Satoh, M., Santee-Cooper, S. M., Ware, C. F., Togawa, A., Nishikawa, S., and Nishikawa, S. (2002). Different cytokines induce surface lymphotoxin-alphabeta on IL-7 receptor-alpha cells that differentially engender lymph nodes and Peyer's patches. Immunity 17, 823-833.

Conflict of Interest Statement: The authors declare that the research was conducted in the absence of any commercial or financial relationships that could be construed as a potential conflict of interest.

Received: 04 June 2012; accepted: 28 June 2012; published online: 12 July 2012. Citation: den Haan JM, Mebius $R$ and Kraal $G$ (2012) Stromal cells of the mouse spleen. Front. Immun. 3:201. doi: 10.3389/fimmu.2012.00201

This article was submitted to Frontiers in Antigen Presenting Cell Biology, a specialty of Frontiers in Immunology. Copyright (C) 2012 den Haan, Mebius and Kraal. This is an open-access article distributed under the terms of the Creative Commons Attribution License, which permits use, distribution and reproduction in other forums, provided the original authors and source are credited and subject to any copyright notices concerning any third-party graphics etc. 